\title{
Balancing food, activity and the dangers of sunlit nights
}

\author{
Sonny S. Bleicher ${ }^{1,2}$ (D) $\cdot$ Haapakoski Marko ${ }^{2}$ Dana J. Morin ${ }^{3} \cdot$ Käpylä Teemu ${ }^{2} \cdot$ Ylönen Hannu ${ }^{2}$
}

Received: 20 February 2019 / Revised: 30 April 2019 / Accepted: 8 May 2019 / Published online: 25 June 2019

(C) The Author(s) 2019

\begin{abstract}
Living in northern latitudes poses challenges to the animals that live in those habitats. The harsh environment provides a short breeding season where the sunlit summer nights provide little reprieve from visibility to predators and increased risk. In this paper, we tested the activity and food choice patterns of bank voles Myodes glareolus in early spring season, categorized by $18 \mathrm{~h}$ of daylight and $6 \mathrm{~h}$ of dusk in every day cycle. We found that territorial females showed a less predictable pattern of activity than males that were most active during the hours of dusk. The voles also showed preference to forage on high carbohydrate foods at sunset, while switching over to a more protein and fat-based diet towards sunrise. This shift is suggestive of a diet that is a direct adaptation to day-long fasts. Our results suggest a sensitive mechanism between food choice and predator avoidance in a system where light summer nights increase the predation risk considerably.
\end{abstract}

\section{Significance statement}

Bank voles, Myodes glareolus, are considered a model organism in ecological studies and have been used for studies of population cycles, predator-prey interactions and studies of territoriality with over a century of published records. In this study, we challenge two major preconceptions about these animals using behavioral bio-assays in a controlled environment. (1) We challenge the diurnal activity patterns of these rodents currently accepted to have a bi-modal distribution in summer months and show a unimodular activity pattern. And (2) we show that these animals are not opportunistic foragers but vary their diet to compensate for the stress of an extended daytime fast further supporting a nocturnal pattern of activity even in extreme sunlit nights where night lasts under an hour.

Keywords Foraging ecology $\cdot$ Subarctic forests $\cdot$ Vole-weasel model system $\cdot$ Sex bias and social behaviour $\cdot$ Evolutionary game theory $\cdot$ Physiological energetics

\section{Introduction}

Life in northern latitudes presents a unique and challenging environment in many ways. Of particular importance are

Communicated by A. G. Ophir

Electronic supplementary material The online version of this article (https://doi.org/10.1007/s00265-019-2703-y) contains supplementary material, which is available to authorized users.

Sonny S. Bleicher

bleicher.s.s@gmail.com

1 Environmental Sciences and Policy Department, George Mason University, Fairfax, VA, USA

2 Department of Biological and Environmental Science, Konnevesi Research Station, University of Jyväskylä, Jyväskylä, Finland

3 Department of Wildlife, Fisheries and Aquaculture, Mississippi State University, Box 9680, Mississippi State, MS 39762, USA harsh conditions and distinct dualism in light regime between summer and winter. Summers are rich in food, a result of uninhibited plant growth responding to the lack of a light constraint, which fuels intense reproduction and rearing of young. The best indication for this comes from the example of rich insect fauna sustaining the high numbers of longdistance migrants in birds (Somveille et al. 2015). Resident animals face the sunlit nights in summer and little or no light coupled with frozen and harsh living conditions in winter. Both summer lightness and winter darkness have strong consequences for predator prey interactions in resident prey, like small rodents. The harsh conditions in winter translate to significant competition for resources between prey species in summer (Dupuch et al. 2013), and competition for prey in their predators increasing the predation risk.

Small mammals living in northern latitudes breed within a short season lasting between 4 and 5 months in near-arctic latitudes (Lambin et al. 1992; Agrell et al. 1996). The energetic demands of breeding and rearing young in such short 
time frames forces northern small mammals to forage for long hours and under varying levels of intense predation risk by mammalian predators and raptors, owls, skuas, and even shrikes (Sundell 2006), as exhibited in the example of the lemmings above (cf. Dupuch et al. 2013).

Worldwide, ground-dwelling small mammals are predominantly nocturnal (Bennie et al. 2014). Presumably, nocturnal activity is an adaptive strategy to minimize risk of predation (Kotler et al. 2010) and is supported by heightened olfactory and auditory senses that allow detection of risks in low light conditions and benefit from the weakness of predators to identify the location of these mammals (Webster and Strother 1972; Herman and Valone 2000). The benefit of nocturnal activity is challenged in the arctic and near-arctic latitudes by summers that are categorized by short or non-existing nights. Sunlit nights force foragers into crepuscular and even diurnal activity patterns (Ylönen et al. 2006). Foraging in daylight increases the risk of predation foragers experience (both perceived and actual) driving the energetic demands they must invest in vigilance behaviors (Brown 1999). Given this tradeoff of food and safety, we can predict that while activity is possible day round (Ylönen et al. 1988), the majority of spring-summer foraging activity should be concentrated in the hours between dusk and dawn, where the shadows provide a bit more camouflage. In this experiment, we set out to affirm this assumption and challenge some observations that suggest that such small mammals are active throughout the day because of the limited "night" in those northern latitudes.

To test the needs of foragers in a risky sunlit environment we turned to a model system for population dynamics and predator-prey interactions, the bank vole, Myodes glareolus, and its behaviors to avoid predation risk from its most prevalent predator the least weasel Mustela nivalis (Jędrzejewska and Jędrzejewski 1990; Korpimäki et al. 1991; Norrdahl and Korpimäki 1995; Ylönen et al. 2003; Sundell and Ylönen 2004). Given how much is known about the interactions between these species, they provided an opportunity to delve into the anti-predator behaviors and how they diverge from the common assumptions currently accepted about them. We trapped a population of bank voles from its natural mixed forest environment at the beginning of spring in March-April, before the first snow melt, and before the start of breeding activities (Eccard and Ylönen 2001). We brought the animals into the lab and housed them in celibate conditions under a long-day light regime replicating the outdoor conditions. Given these experiments were run with wild-caught voles, a short time after capture, we expected the behavioral responses to the environmental conditions (where risk a constant) to be identical to that of animals in the wild (cf. Troxell-Smith et al. 2016).

In an aim to isolate the effect of predation risk from that of competition (both inter- and intraspecific), we used interview chambers, a system combining optimal patch-use using foraging trays (Brown 1988) with a Y-maze configuration of test treatments where an individual is asked to rank its preference of patches with varying food quality (e.g., Bleicher and Dickman 2016; Bleicher et al. 2018a, b). In these short experiments, we "interviewed" the voles and asked them to rank their preference of food sources at different times of the day. We offered them the choice between high protein fatty sunflower seeds, high protein and high carbohydrate oats, and high carbohydrate low protein millet (Table 1). Given the animals are foraging in "optimal," risk-free condition, we can make the assumption that the decision-making process is driven by food qualities and energetic demands. Thus, we predicted that the voles would:

1. Be more active during "night time" than during sunlit hours.

2. Forage above basal rate at sunset to compensate for a long day fasting, and again increase foraging before sunrise to prepare for the day-long fast.

3. Exhibit a more distinct temporal pattern in males who are not burdened by energy demanding reproductive behavior such as pregnancy and nursing.

4. Select foods that take longer to digest (fats and proteins) towards the end of the night to support the day-long fast.

\section{Methods}

\section{Study species}

The bank vole is one of the most common small rodents in northern temperate and boreal forests (Stenseth 1985). It is granivorous-omnivorous (Hansson 1979) and can live in a wide range of forest habitats. Bank voles can breed in Central Finland 3-4 times within a breeding season from May to September. Their average litter size is 5-6 pups. Bank voles are prey for a diverse predator assemblage which includes the least weasel and the stoat, Mustela erminea (Ylönen 1989).

\section{Research site}

The study was conducted at the Konnevesi Research Station of the University of Jyväskylä, $70 \mathrm{~km}$ north of Jyväskylä. We conducted the experiments in the laboratory and the bank voles were trapped from the forests surrounding the research station $(62.68 \mathrm{~N}, 26.28 \mathrm{E})$ as well as in the forests near Oulainen (64.30 N, 24.82 E) between March and April 2018. The voles were housed in solitary standard transparent laboratory rodent cages $\left(43 \times 26 \times 15 \mathrm{~cm}^{3}\right)$ with a wire mesh cover. Wood chips were used to keep the cages dry, hay was provided as bedding material, rodent food pellets, and fresh water were available ad lib. Long-day light:dark time ratio in the animal rooms was set to 
Table 1 Mean nutritional value of foods per $100 \mathrm{~g}$ and for each item of each resource type. (USDA Food Comparison Database (Moshfegh 2018))

\begin{tabular}{llll}
\hline Per 100 g/per unit & Millet (low quality) & Oat (mid quality) & Sunflower seed (high quality) \\
\hline Energy (kJ) & $1582 / 0.9$ & $1628 / 5.1$ & $2445 / 21.1$ \\
Carbohydrates (g) & $72.8 / 0.04$ & $66.3 / 0.21$ & $20 / 0.17$ \\
Fats (g) & $4.2 / 0.002$ & $6.9 / 0.2$ & $51.46 / 0.44$ \\
Protein (g) & $11.9 / 0.01$ & $16.9 / 0.05$ & $20.78 / 0.18$ \\
Units (seeds) per 100 g & 1760 & 319 & 116 \\
\hline
\end{tabular}

18:6 h, which corresponds roughly to the natural light-dark regime during the experimental period, where also the nigh is partly lit, dusk like, and not dark. The animals used for the foraging experiments (see below) were removed from adlibitum food 4 days prior to the experiment and put on a diet of poor quality food, $3 \mathrm{~g}$ of millet per day, that met the basic energetic needs of these animals (cf. Eccard and Ylönen 2006). The change to a poor diet was given as an incentive for the animals to keep foraging in the novel environment of our study systems and counteract neophobia expected in satiated animals (Amézquita et al. 2013).

\section{Study system design}

Two separate experiments were conducted: one foraging experiment that used 35 individual voles and one observational experiment that used 122 voles. The voles that took part in the foraging experiment were not reused for the second experiment.

\section{Foraging experiment}

Two interview chambers were constructed in concordance with Bleicher et al. (2018a, b) and Bleicher and Dickman (2016). Each chamber was constructed from a 30-cm diameter bucket (as a nest box) attached by 5-cm diameter, 30-cm-long PVC tubing to three gray plastic storage bins (rooms) $66 \times$ $45 \times 27 \mathrm{~cm}$ high (Appendix S1) which included a cover. Each room was equipped with a square $(10 \times 10 \times 20 \mathrm{~cm}$ high $)$ box (henceforth patch) with two 5-cm diameter holes drilled in the side to allow access of the vole. Each patch was filled with 11 of sand, and each patch was set with $1.5 \mathrm{~g}$ of a different food source, millet, unhusked oats, or sunflower seeds (in the shell). At the start of every round, a single vole was placed in the nest box and had access to each of the different food patches via the PVC tubing. Each vole was allowed $2 \mathrm{~h}$ to forage, following the protocol of Bleicher (2012), and the expectation that this allowed sufficient time for voles to move between and forage in the different food-density trays.

Brown (1988) stated that an animal foraging in a patch will quit harvesting when the costs associated with resourceharvesting coupled with the costs associated with predation risk equal the energetic value of the patch as perceived by the forager. In this experiment, voles were "asked" to compare patches of different intrinsic value in the absence of predation risk. As the vole depletes a patch, the diminishing returns render other patches more valuable (a missed opportunity cost). The difference in missed opportunity costs drives animals across the landscape (between rooms of the chamber) examining and comparing patches (Smith and Brown 1991; Berger-Tal and Kotler 2014). At the end of each round, the amount of resources the forager did not use in the patch due to the aforementioned costs is the giving-up density (GUD). We first used the systems to run two 24-h experiments, to determine a baseline activity pattern where the voles would reliably forage, and calibrate the habituation patterns of the voles. After this pilot, we ran up to five rounds ( 2 h each) per "night."

Each individual vole was "interviewed" for two nightrounds (Bleicher 2012) and one day-round. At the end of each round, the animal was removed and returned to its holding container and fed with extra millet. Each of the patches was sieved and the weight of remaining resource recorded to obtain the GUD. To avoid the possibility of directional bias in selection of patches by the voles, we positioned the food treatment trays in different cardinal directions in each of the two systems. The systems were reset after each round with fresh new patches and the next round run with a new vole.

On April 24, 2018, all the voles used were removed from ad-libitum feeding and were put on a diet of $3 \mathrm{~g}$ of millet daily. Over the period April 27-May 4, 2018, adult wild-caught voles were run through the interview chambers. Of the 35 animals used, 21 were non-gravid females and 14 were males. To remove all environmental (e.g., temperature), temporal (i.e., round of the night), directional (cardinal direction), and individual system effects, we calculated averages per individual within each of the food treatments (cf. Bleicher 2012; Bleicher et al. 2018a, b). The risky element of these chambers is their novelty, i.e., producing neophobia. To avoid habituation, we set the 2-h limit per round.

\section{Observational experiment}

Between the 6th and 8th of May 2018, we monitored the activity, especially locomotion, in all the 122 captive voles in the lab. For 48 consecutive hours, we visited each of the three husbandry rooms at the station. Once per hour, we logged whether 
movement was observed in each cage. Of the 122 voles, 42 voles were housed together for copulation. Twelve additional voles did not appear active for more than $2 \mathrm{~h}$ in our sampling period and thus were omitted from the dataset. These corrections resulted in 89 caged being monitored hourly. We used 60 male voles and 62 females for analyses. All males (38) were categorized as solitary. While of the female voles one was gravid, 10 were nursing and 19 were solitary individuals.

\section{Data analyses}

Our experiment was divided into two units, one manipulative and one observational. Therefore, the analyses are divided into two sections as well, one for locomotion and one for the foraging tenacity.

To quantify the voles' activity patterns in their cages, with forage unrestricted, as described in the experimental set up, we summarized diel activity patterns (active or sedentary) for individuals falling within four groups: solitary males, solitary females, coupled males and females, and nursing females. We used temporal kernel density functions to describe activity as demonstrated in Ridout and Linkie (2009) using the overlap package (Meredith and Ridout 2017) in R (R Development Core Team 2016).

For the foraging activity, we used three methods to determine whether the voles selected patches based on the resource-type or if that selection was variable based on time of day. First, we tested whether the voles ranked the food resources equally using Friedman's test of concordance (manually calculated). We ranked the amount of resources used in each treatment from 1 to 3 (3 being the highest weight consumed, i.e., the lowest GUD).

For the second analysis, we calculated the mean harvested mass (1.5-GUD) of food as a function of hour of the day $x$ food type $\times$ sex. The cleaned dataset had a sample size of 76 mean values. We ended up collecting data points at 142 -h rounds as opposed to the 12 rounds that were in the original experimental design. The slight difference is a result of the time it takes to reset the experiment between rounds averaging at $12 \mathrm{~min}$. In Systat 13, we ran an analysis of variance (ANOVA) using the harvest mass as the dependent variable and food type, sex and sex $\times$ food type as dependent variables. We added the hour of the day as a covariate. For significant factors, we ran post-hoc pairwise comparisons with Tukey's honestly significant difference (THSD) tests.

Last, to rank the importance of the variables from the perspective of the voles, we used a Bayesian approach and ran two random forest regression analyses. These analyses, best described as categorical principle-component analyses, formulate a machine-learning model in shape of a decision-tree based in the existing data. The resulting tree is a prediction of the importance of factors using point clusters in a multi-axis space. This model mines the dataset and ranks the categorical splits that explain the greatest amount of data points in the data set. Within each of the nodes (categorical splits), it repeats the analysis on the data points with the category. The resulting output provides an importance statistic, a table providing the shape of the decision tree and model strength statistics. At each node, the model produces the mean of the dependent variable $(\mu)$, the number of data points described by the node $(\mathrm{N})$, and the variance of the dataset represented in the node. We ran these analyses in StatSoft (C) Statistica 8. To bolster the predictive strength of these models, we used the raw data as collected in the experiment. We first ran this analysis on the entire data set $(24 \mathrm{~h}$ of foraging data), and then post-hoc, reran the analysis with data from the peak activity (discussed below) between 18:00 and 6:00. In these analyses, we used GUD as the dependent variable. We used sex and food type as categorical variables and hour of day and experimental system as numeric variables. This analysis suggests the likely categorical splits, nodes, but do not constitute a statistical pairwise comparison.

\section{Data availability statement}

All data generated or analyzed during this study are included in this published article [Appendix S5].

\section{Ethics}

All applicable international, national, and/or institutional guidelines for the use of animals were followed). The study was conducted under permission for animal experimentation ESAVI/6370/04.10.07/2014 from the ethics committee of the University of Jyvaskyla. No animals were harmed in this experiment and the stress was limited as much as possible especially to pregnant and nursing females that were not used in the manipulative foraging section of this experiment.

\section{Blinded methods}

It was not possible to record data blind because our study involved focal animals in the lab. However, we used population level data to minimize bias.

\section{Results}

\section{Temporal activity analysis}

The temporal activity analysis (script available as Appendix S2) suggested that while the bank voles were occasionally active day round, the majority of the population diel activity occurred during the period designated as "dusk" between 23:00 and 5:00 (Fig. 1a). Solitary males and coupled animals (males and females housed together) adhered to a primarily nocturnal activity pattern. Solitary females were the group that 


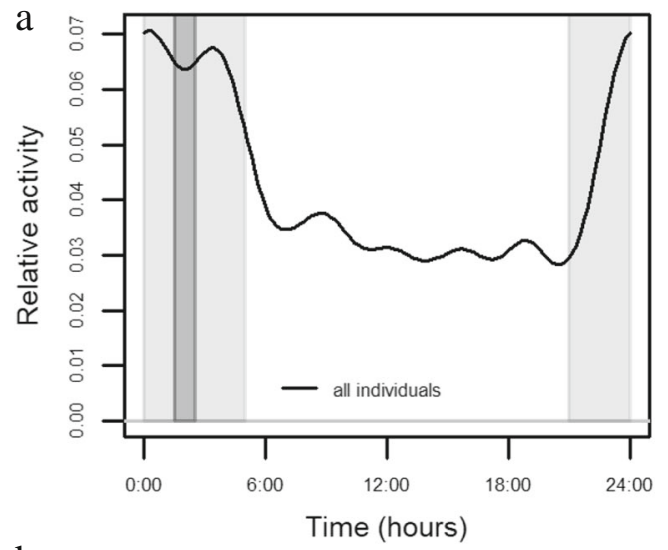

b

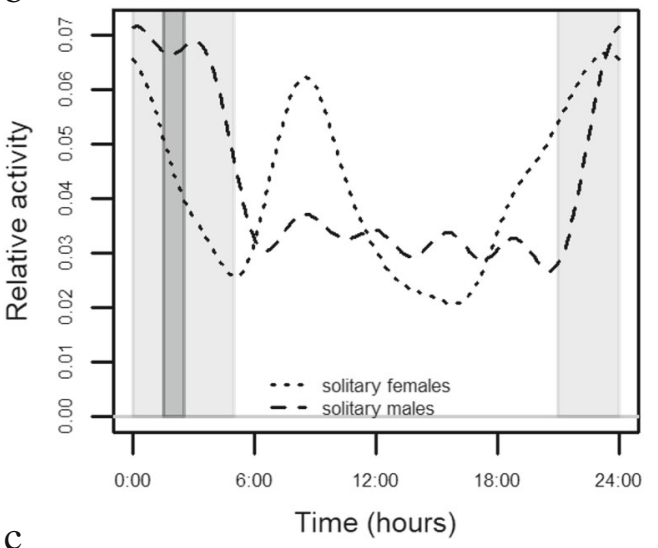

C

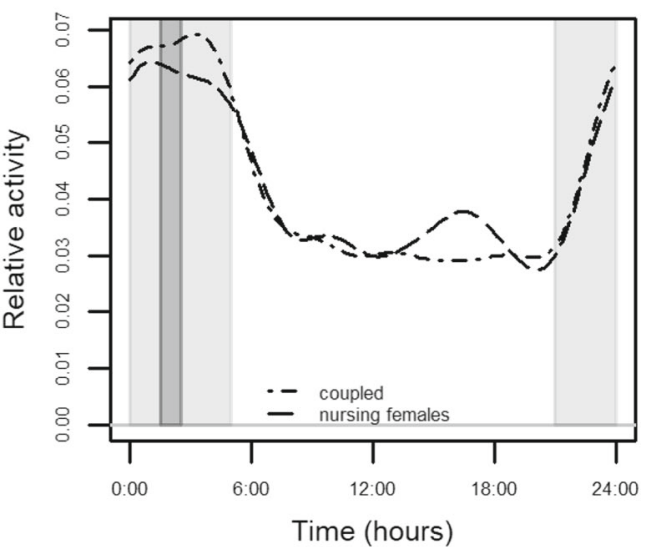

Fig. 1 Temporal activity kernel densities for captive bank voles demonstrating relative activity over the diel period. Activity was measured as movement in a cage at each hour for a 48-h period (solitary females $=19$, solitary males $=39$, coupled males and female $=$ 42 , nursing females $=10$ ). The top panel (a) represents all individuals, the central panel (b) only solitary individuals, and the bottom one (c) individuals that were housed with other individuals (nursing mothers or mating couples). The shaded areas in the figure represent states of darkness, where light gray is twilight and dark gray is full night conditions

diverged the most with a bi-modal activity pattern, specifically a second peak in activity around 7-8 am (Fig. 1b). Nursing mothers exhibited a mostly nocturnal pattern, but with occasional low levels of activity mid-day (Fig. 1c).

\section{Foraging activity}

In Friedman's test of concordance, the voles strongly agreed on their preference of food choice $\left(\mathrm{F}_{m}=445.77, N=35\right.$, $p<0.01, W=3$ ). A pairwise comparison showed voles had a clear preference for sunflower seeds $(r=97)$ over millet $(r=$ $58)$ or oat $(r=57)$ where $r$ is the ranks sum.

The ANOVA $\left(N=76, R^{2}=0.678\right)$ showed that time of day, sex, and food type all significantly affected the foraging of the voles (Table 2). The harvest pattern showed a clear preference for the sunflower seeds followed by the oat and millet (Fig. 2). Post-hoc pairwise comparison (THSD) found that there was no difference between the oat and the millet, but both were significantly lower than the sunflower (both $p<0.01$; Appendix 3). The male voles harvested more than females \pm $\mathrm{SE}$ (standard error): $0.3 \pm 0.021 \mathrm{~g}$ and $0.224 \pm 0.019 \mathrm{~g}$, respectively. Last, the foraging appeared to be greater during the "night" hours 18:00-4:00 than during "day time" (Fig. 3a). While the foraging on sunflower seeds was constant throughout the day, we observed an increase of foraging in the oat and millet at night and a short burst mid-morning (Fig. 3b).

The random forest regression analysis forecasting the relevance of food type, sex, system (I or II), and time of day generated a model with risk estimates \pm SE of $0.058 \pm 0.008$ and $0.069 \pm 0.018$ for training and testing, respectively. The model ranked the food type as the greatest ranking variable with an importance of 1.0 followed by time of day, sex, and system with importance ranks of $0.82,0.345$, and 0.262 , respectively. This analysis suggests a divergence between the sexes in foraging sunflower seeds with male foraging slightly more of this food type. In addition, it finds a greater sex-bias in the oat and millet with females foraging more in the afternoon and early evening (Fig. 4a, Appendix S4).

After running the ANOVA mentioned above, it seemed pertinent to address the changes in foraging at the peak of the voles' activity and not when they are sedentary. Therefore, we repeated the analysis for a subset of the data collected between 18:00 and 6:00. The new model's risk

Table 2 ANOVA table $\left(N=76, R^{2}=0.678\right)$ for a model using mass of harvested resources averaged by time of day as a dependent variable to compare foraging activity of 35 voles in relation to the sex of the individual, the food type offered for its selection and with the time of day as a covariate

\begin{tabular}{llrlrl}
\hline Variable & SS & df & Mean squares & \multicolumn{1}{l}{$F$} & \multicolumn{1}{l}{$p$} \\
\hline Food & 0.901 & 2 & 0.450 & 32.519 & 0.000 \\
Sex & 0.100 & 1 & 0.100 & 7.199 & 0.010 \\
Food $\times$ sex & 0.061 & 2 & 0.031 & 2.207 & 0.119 \\
Hour & 0.542 & 13 & 0.042 & 3.009 & 0.002 \\
Error & 0.789 & 57 & 0.014 & & \\
\hline
\end{tabular}

$S S$, sum of squares; $d f$, degrees of freedom; $M S$, mean squares; $F$, F ratio; $p, p$ value; Food, food type 


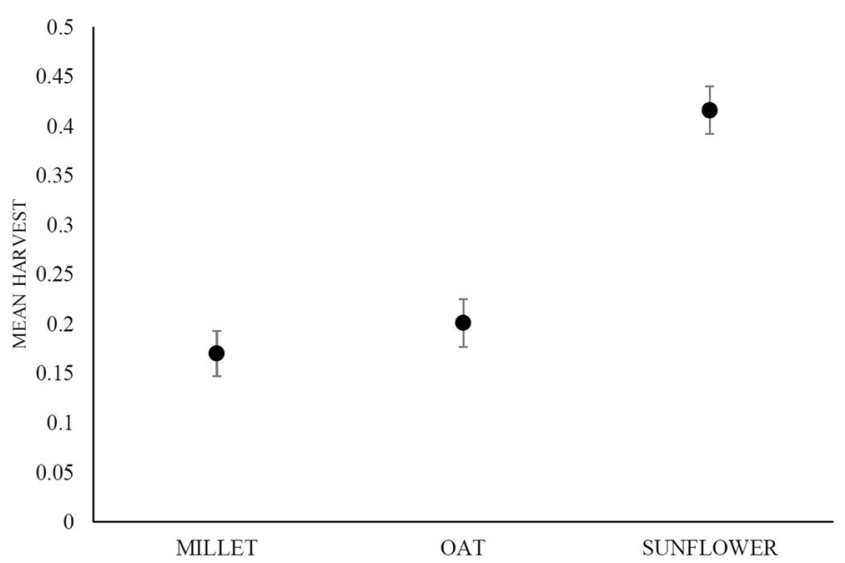

Fig. 2 Mean harvest $(\mathrm{g}) \pm \mathrm{SE}$ as reflected in patches with sunflower seeds (high protein and fat), oat (high carbohydrate), and millet (poor quality forage)

estimates were $0.058 \pm 0.012$ and $0.113 \pm 0.035$ for training and testing, respectively. Similar to the original model, the food type and time of day were ranked the most important variables with ranks of 1.0 and 0.469 respectively. The system increased in importance to a rank of 0.312 while sex
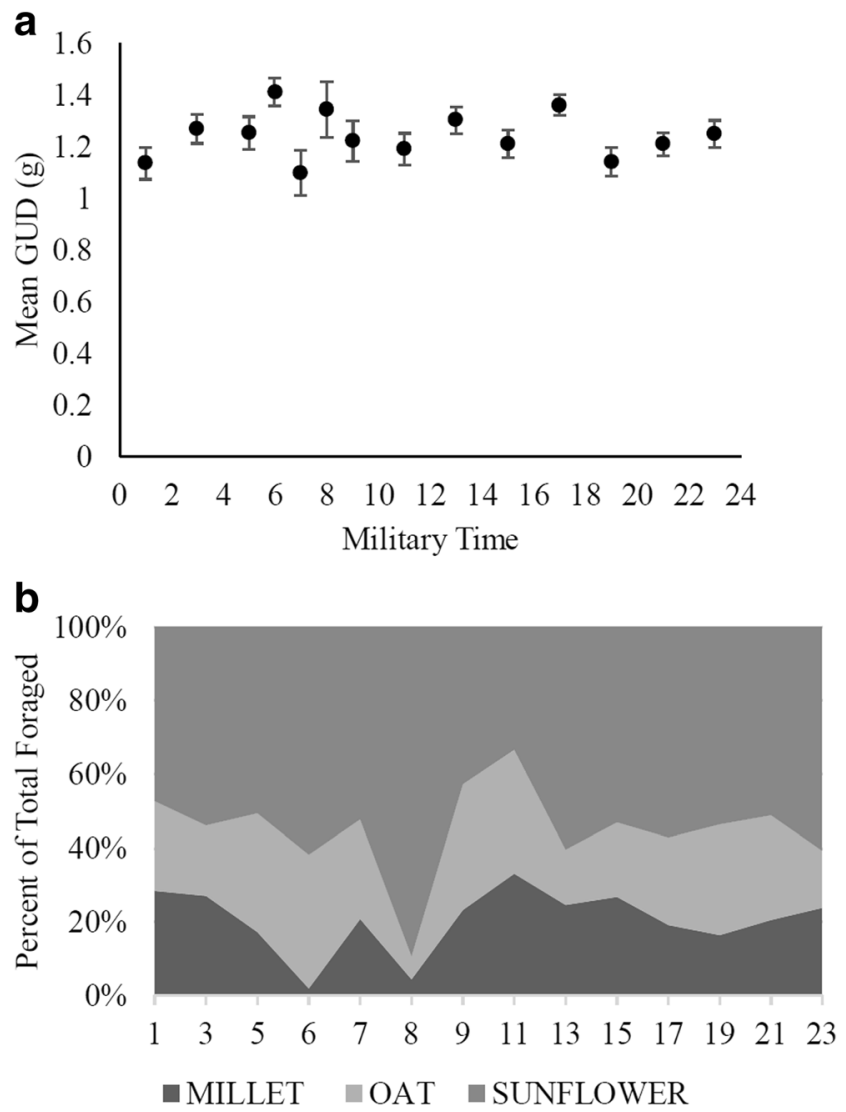

Fig. 3 Visualization of foraging activity of voles throughout the day (in 2-h segments) measured in a giving-up density GUD (g) \pm SE and b proportion of harvested food sources by seed type. The sunlight cycle at this time of year included a darkness period of around $1 \mathrm{~h}$. The sun-began to set around $21: 30 \mathrm{~h}$, reached darkness at 1:30, rose again to twilight at 2:30 emerged fully by $5: 30$ am diminished to a rank of 0.224 . Under the new model, the separation of sunflower seeds to its own category remained; however, foraging on oat and millet were divided to separate nodes (Fig. 4b, Appendix S4). While under this new model, foraging on millet was consistent throughout the night, the foraging on both sunflower seeds and oat varied based on the time of night. Foraging on sunflower seeds increased later in the night and decreased on oat (Fig. 5).

\section{Discussion}

Contrasting our experiments with previous studies, two major consequences are revealed. First, that voles show a preference for activity during the short nocturnal cycle, despite of its consequences of long fasting during long and light days. And second, that they can be forced by energetic demands into this peculiar, previously not described diel activity by environmental and social conditions, such as food shortages, increased competition when paired for mating, or due to energetic needs of nursing.

Before we discuss the different findings of our experiments, we must highlight the question driving this discussion, i.e., why the energetic needs impact the foraging behavior in voles. The chronic stress under-which animals live varies based on a number of constant and variable factors (Boonstra 2013). These include resource competition (e.g., Morris 2003; Ovadia et al. 2005) and ambient risk of predation. This risk is manifested in habitat structure (Bleicher 2017), shelter availability (Abu Baker and Brown 2010), the activity of predators in the environment (Bleicher et al. 2016, 2019; Kotler et al. 2016), and the most relevant to our study are ambient illumination (Longland and Price 1991; Kotler et al. 2010) including photoperiodic length. Light cycles shift behavioral patterns of foragers and cause variation in stress hormones production (Borniger et al. 2017). Those stress hormone levels impact at the core behaviors in small mammals such as deer mice (Borniger and Nelson 2017) including the following: copulating, information processing, and aggression. Given these examples, it is only logical that the same neurological impacts of photoperiodic length would also affect the foraging decisions in our test voles.

Our experiment showed an adaptation to day-long fasting and found a direct linkage between the times of day an animal is put in a system to forage and the type of food that is harvested. We attribute the differences to the daily stress of living in high latitudes with the unique light regime exposing the ground-dwelling small rodent more to predation if active during the light time. The majority of small mammals are presumably nocturnal, as an adaptation for the management of risk from predators and are known to respond with increased stress correlated with increase in ambient light (Prugh and 
Fig. 4 Decision-trees based on random forest regression analysis monitoring foraging tenacity measured in giving-up densities corresponding to a 24-h time period and $\mathbf{b}$ subset of only peak activity between 18:00 and 6:00. The tree corresponds to the largest subset of data points that cluster in multidimensional space. Each level of nodes represents a subcluster within the original group. Values for the tree structure can be found in corresponding Tables A and B in ESM4. Bold text boxes represent final nodes a

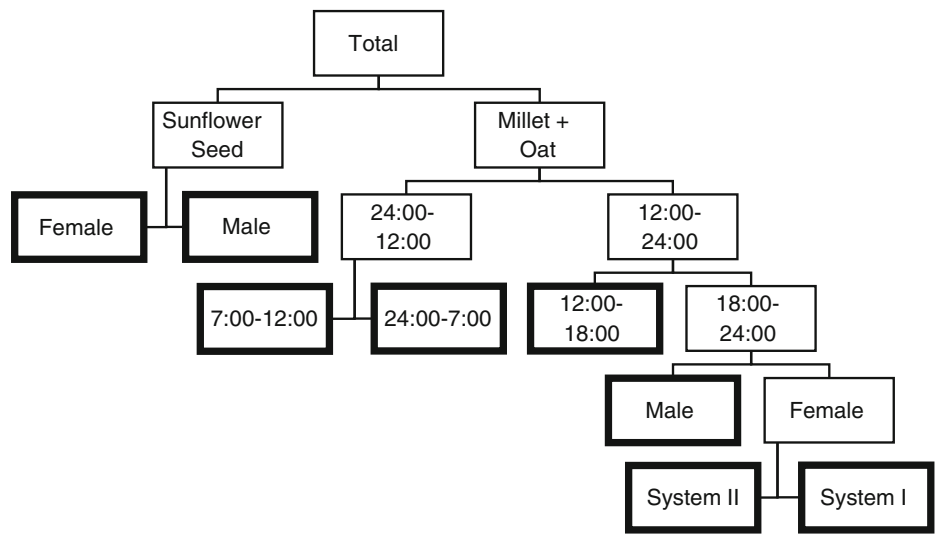

b

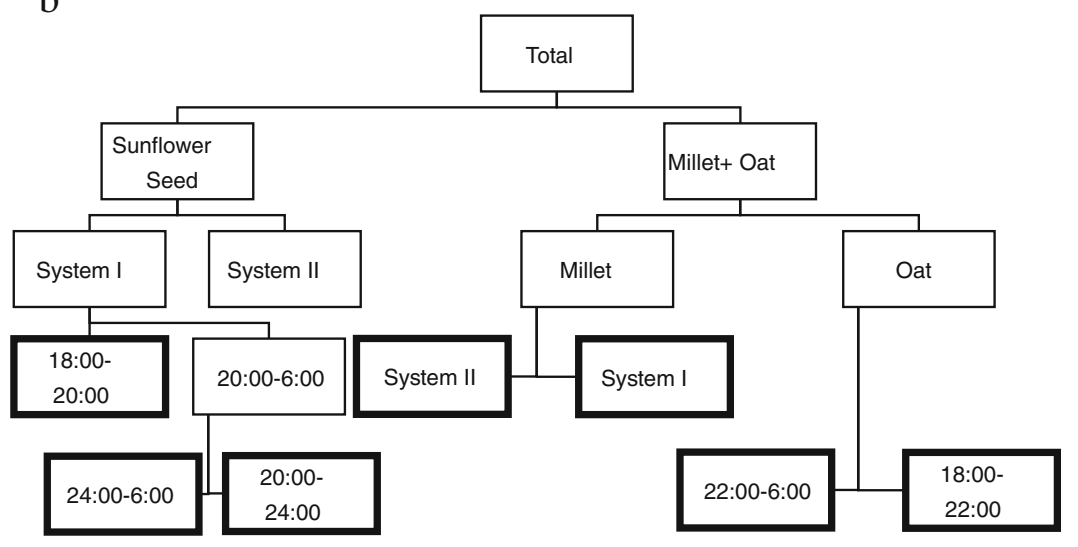

Golden 2014). For voles inhabiting the areas where we were running our experiment, the long days mean that they have limited time to forage in semi-safe illumination. Specifically, 4-6 h of dusk and dawn.

Manipulating, handling, and relocating animals from an environment to which they are habituated generally causes

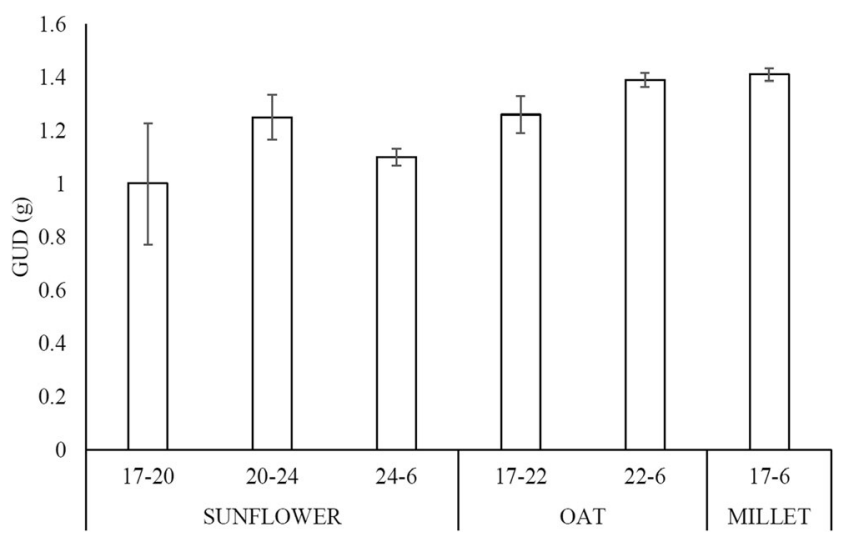

Fig. 5 Nightly shifts in foraging activity (reflected by giving-up densities $\mathrm{GUD} \pm \mathrm{SE}(\mathrm{g}))$ as a factor of food type as predicted by the Random Forest Regression Model for peak activity (Fig. 4b, Appendix S2). Each of the food sources should be observed as independent as they are sourced in different nodes of the tree with different sample sizes physiological stress responses which translate into alterations in behavioral patterns these animals exhibit (e.g., Rosellini and Widman 1989; Ylönen et al. 2006). Perhaps the best example of behavioral adaptations to stress comes from our own species, humans that compensates for stress through foraging (e.g., Wolff et al. 2000). Our experiments show different patterns between the manipulations, in the interview chambers, and the observations in the animal room. From other experiments, we find evidence that use of bioassays to measure animal behavior will always be associated with extra stress. Taking animals out of their holding pens and transferring them into a novel and sterile environment will at the minimum produce neophobia (Bolbroe et al. 2000) and at more extreme cases even cause animals to cease activity all together (Bleicher et al. 2018a).

The differences we found between our interviews and the holding pens suggest that we can artificially prompt animals to change their foraging strategy by moving them out of the environment they are habituated to. Matching the experimental chambers with the natural setting and within the temporal activity limits of the animals may provide a more realistic picture of how the animals actually understand the tradeoffs of food and safety, using measurements within the evolutionary capabilities of the species, their "umwelt" (cf. von Uexküll 1909). Logically, we could attribute the preference for high sugar and starch foods 
whose energy can be accessed quickly as a compensation for the energetic costs of the stress; however, if we combine these results with the temporal patterns that emerged, we reach very different conclusions.

In our observations of the activity patterns of voles, we found strong evidence that sharing your space with either a mate, or offspring caused sporadic activity, increased immediate energy need and increased the likelihood of individuals to be active during the daytime. We believe that it is not the same factor that causes both these observed patterns. During breeding season, voles are solitary animals (Horne and Ylönen 1996) and only couple for short periods of mating time. The females are territorial and the males move around between female territories (Ylönen et al. 1988). When the males are housed socially with a female, the females are responding to the breach of their territory. This continued constraint likely forces the females to chase after the males and the males to try to sneak in copulations. Nursing females, in contrast, are forced to forage as a means to compensate for the energetic strain that feeding litters of 3-6 pups puts on them (Trebatická et al. 2007).

If the voles start to forage after the long-day fasting, this would logically explain the preference for the high-energy oats early on. However, after regaining the needed energy, they change their foraging strategy and prefer sunflower seeds, high in fat and protein (Fig. 5). We can best attribute this shift to the sunflowers, as a shift to slow-releasing energy food sources (Krogh et al. 1920) that would help sustain the voles during the long day's fast - until the start of the next foraging period $18 \mathrm{~h}$ later.

To conclude, our study is among the first that aims to describe how natural high-latitude light regime determines changes in animal foraging and antipredator strategies (e.g., Norrdahl and Orpimäki 1998; Dupuch et al. 2013). With careful monitoring of the social and diet quality effects in foraging decisions during the short night or dusk, we addressed some of the constraints that resident species in that northern latitude face during sun-lit summer nights. While many rodents are strictly nocturnal (e.g., Longland and Price 1991; Kotler et al. 1993), the ambient illumination of the northern summer nights forces the local species, reluctantly, to be active in a diurnal pattern. The energetic demands of long fasts coupled with high breeding rates do not allow for hoarding during the breading season and forces these animals to compensate for these costs through food choices (Xia and Millar 1988). The last conclusion we drew from this study is that the voles altered their behaviors based on social interactions. Solitary voles optimized their activity while individuals carrying the reproductive burden in were forced into more diurnal activity.

Acknowledgments We thank the technical staff of the Konnevesi Research Station for building study systems. We also thank the reviewers for a thorough review and the help in making this a stronger and more cohesive paper.
Funding Open access funding provided by University of Jyväskylä (JYU). This research was supported by a Finnish Academy grant, 2015-2019 for HY, \# 288990, 11.5.2015.

\section{Compliance with ethical standards}

Conflict of interest The authors declare that they have no conflict of interest.

Ethical approval The study was conducted under permission for animal experimentation ESAVI/6370/04.10.07/2014.

Open Access This article is distributed under the terms of the Creative Commons Attribution 4.0 International License (http:// creativecommons.org/licenses/by/4.0/), which permits unrestricted use, distribution, and reproduction in any medium, provided you give appropriate credit to the original author(s) and the source, provide a link to the Creative Commons license, and indicate if changes were made.

\section{References}

Abu Baker MA, Brown JS (2010) Islands of fear: effects of wooded patches on habitat suitability of the striped mouse in a South African grassland. Funct Ecol 24:1313-1322. https://doi.org/10. 1111/j.1365-2435.2010.01757.x

Agrell J, Erlinge S, Nelson J, Sandell M (1996) Shifting spacing behaviour of male field voles (Microtus agrestis) over the reproductive season. Ann Zool Fenn 33:243-248. https://doi.org/10.2307/ 23735780

Amézquita A, Castro L, Arias M, Gonzalez M, Esquival C (2013) Field but not lab paradigms support generalisation by predators of aposematic polymorphic prey: the Oophaga histrionica complex. Evol Ecol 27:769-782. https://doi.org/10.1007/s10682-013-9635-1

Bennie JJ, Duffy JP, Inger R, Gaston KJ (2014) Biogeography of time partitioning in mammals. P Natl Acad Sci USA 111:13727-13732. https://doi.org/10.1073/pnas.1216063110

Berger-Tal O, Kotler BP (2014) State of emergency: behavior of gerbils is affected by the hunger state of their predators. Ecology 91:593-600

Bleicher SS (2012) Heat and humidity alter predation cues in Gerbillus andersoni allebyi. MSc thesis, Ben Gurion University of the Negev

Bleicher SS (2017) The landscape of fear conceptual framework: definition and review of current applications and misuses. PeerJ 5:e3772. https://doi.org/10.7717/peerj.3772

Bleicher SS, Brown JS, Embar K, Kotler BP (2016) Novel predator recognition by Allenby's gerbil (Gerbillus andersoni allenbyi): do gerbils learn to respond to a snake that can "see" in the dark? Isr J Ecol Evol 62:178-185. https://doi.org/10.1080/15659801.2016. 1176614

Bleicher SS, Dickman CR (2016) Bust economics: foragers choose high quality habitats in lean times. PeerJ 4:e1609. https://doi.org/10. 7717/peerj.1609

Bleicher SS, Kotler BP, Brown JS (2019) Comparing plasticity of response to perceived risk in the textbook example of convergent evolution of desert rodents and their predators; a manipulative study employing the landscape of fear. Front Behav Neurosci 13:58. https://doi.org/10.3389/fnbeh.2019.00058

Bleicher SS, Kotler BP, Shalev O, Dixon A, Embar K, Brown JS (2018a) Divergent behavior amid convergent evolution: a case of four desert rodents learning to respond to known and novel vipers. PLoS One 13:e0200672 
Bleicher SS, Ylonen H, Käpylä T, Haapakoski M (2018b) Olfactory cues and the value of information: voles interpret cues based on recent predator encounters. Behav Ecol Sociobiol 72:187

Bolbroe T, Jeppesen LL, Leirs H (2000) Behavioural response of field voles under mustelid predation risk in the laboratory: more than neophobia. Ann Zool Fenn 37:169-178

Boonstra R (2013) Reality as the leading cause of stress: rethinking the impact of chronic stress in nature. Funct Ecol 27:11-23. https://doi. org/10.1111/1365-2435.12008

Borniger CJ, Cisse YM, Nelson RJ, Martin LB (2017) Seasonal variation in stress response. In: Fink G (ed) Stress: neuroendocrinology and neurobiology. Handbook of stress series, vol 2. Academic Press, New York, pp 411-419

Borniger JC, Nelson RJ (2017) Photoperiodic regulation of behavior: Peromyscus as a model system. Semin Cell Dev Biol 61:82-91. https://doi.org/10.1016/j.semcdb.2016.06.015

Brown JS (1988) Patch use as an indicator of habitat preference, predation risk, and competition. Behav Ecol Sociobiol 22:37-47. https://doi. org/10.1007/BF00395696

Brown JS (1999) Vigilance, patch use and habitat selection: foraging under predation risk. Evol Ecol Res 1:49-71

Dupuch A, Morris DW, Halliday WD (2013) Patch use and vigilance by sympatric lemmings in predator and competitor-driven landscapes of fear. Behav Ecol Sociobiol 68:299-308. https://doi.org/10.1007/ s00265-013-1645-Z

Eccard JA, Ylönen H (2001) Onset of spring reproduction in the bank vole (Clethrionomys glareolus): a matter of food, competition or density? Can J Zool 79:1743-1753

Eccard JA, Ylönen H (2006) Adaptive food choice of bank voles in a novel environment: choices enhance reproductive status in winter and spring. Ann Zool Fenn 43:2-8

Hansson L (1979) Condition and diet in relation to habitat in bank voles Clethrionomys glareolus: population or community approach? Oikos 30:55-63

Herman C, Valone T (2000) The effect of mammalian predator scent on the foraging behavior of Dipodomys merriami. Oikos 91:139-145. https://doi.org/10.1034/j.1600-0706.2000.910113.x

Horne TJ, Ylönen H (1996) Female bank voles (Clethrionomys glareolus) prefer dominant males; but what if there is no choice? Behav Ecol Sociobiol 38:401-405. https://doi.org/10.1007/ s002650050257

Jędrzejewska B, Jędrzejewski W (1990) Antipredatory behaviour of bank voles and prey choice of weasels - enclosure experiments. Ann Zool Fenn 27:321-328

Korpimäki E, Norrdahl K, Rinta-Jaskari T (1991) Responses of stoats and least weasels to fluctuating food abundances: is the low phase of the vole cycle due to mustelid predation? Oecologia 88(4):552-561

Kotler BP, Brown JS, Bleicher SS, Embar K (2016) Intercontinental-wide consequences of compromise-breaking adaptations: the case of desert rodents. Isr J Ecol Evol 62:186-195. https://doi.org/10.1080/ 15659801.2015.1125832

Kotler BP, Brown JS, Mukherjee S, Berger-Tal O, Bouskila A (2010) Moonlight avoidance in gerbils reveals a sophisticated interplay among time allocation, vigilance and state-dependent foraging. Proc R Soc Lond B 277:1469-1474. https://doi.org/10.1098/rspb. 2009.2036

Kotler BP, Brown JS, Subach A (1993) Mechanisms of species coexistence of optimal foragers: temporal partitioning by two species of sand dune gerbils. Oikos 67:548-556

Krogh A, Lindhard J, Liljestrand G, Andersen KG (1920) The relative value of fat and carbohydrate as sources of muscular energy. Biochem J 14:290-363. https://doi.org/10.1042/bj0140290

Lambin X, Krebs CJ, Scott B (1992) Spacing system of the tundra vole (Microtus oeconomus) during the breeding season in Canada's western Arctic. Can J Zool 70:2068-2072. https://doi.org/10.1139/z92278
Longland WS, Price MV (1991) Direct observations of owls and heteromyid rodents: can predation risk explain microhabitat use? Ecology 72:2261-2273

Meredith M, Ridout M (2017) Estimates of coefficient of overlapping for animal activity patterns. R CRAN Repository

Morris DW (2003) How can we apply theories of habitat selection to wildlife conservation and management? Wildlife Res 30:303-319. https://doi.org/10.1071/WR02028

Moshfegh A (2018) National nutrient database for standard reference legacy release, https://ndb.nal.usda.gov

Norrdahl K, Korpimäki E (1995) Mortality factors in a cyclic vole population. Proc R Soc B Biol Sci 261(1360):49-53

Norrdahl K, Orpimäki EK (1998) Does mobility or sex of voles affect risk of predation by mammalian predators? Ecology 79:226-232. https:// doi.org/10.1890/0012-9658(1998)079[0226:DMOSOV]2.0.CO;2

Ovadia O, Abramsky Z, Kotler BP, Pinshow B (2005) Inter-specific competitors reduce inter-gender competition in Negev Desert gerbils. Oecologia 142:480-488. https://doi.org/10.1007/s00442-0041726-9

Prugh LR, Golden CD (2014) Does moonlight increase predation risk? Meta-analysis reveals divergent responses of nocturnal mammals to lunar cycles. J Anim Ecol 83:504-514. https://doi.org/10.1111/ $1365-2656.12148$

R Development Core Team (2016) R: a language and environment for statistical computing. R Foundation for Statistical Computing, Vienna, Austria, http://www.R-project.org

Ridout MS, Linkie M (2009) Estimating overlap of daily activity patterns from camera trap data. J Agric Biol Envir St 14:322-337. https://doi. org/10.1198/jabes.2009.08038

Rosellini RA, Widman DR (1989) Prior exposure to stress reduces the diversity of exploratory behavior of novel objects in the rat (Rattus norvegicus). J Comp Psychol 103:339-346

Smith RJ, Brown JS (1991) A practical technique for measuring the behavior of foraging animals. Am Biol Teach 53:236-242

Somveille M, Rodrigues AS, Manica A (2015) Why do birds migrate? A macroecological perspective. Glob Ecol Biogeogr 24:64-674

Stenseth N (1985) Geographic distribution of Clethrionomys species. Ann Zool Fenn 22:215-219

Sundell J (2006) Experimental tests of the role of predation in the population dynamics of voles and lemmings. Mamm Rev 36: 107-141

Sundell J, Ylönen H (2004) Behaviour and choice of refuge by voles under predation risk. Behav Ecol Sociobiol 56(3):263269

Trebatická L, Ketola T, Klemme I, Eccard JA, Ylönen H (2007) Is reproduction really costly? Energy metabolism of bank vole females through the reproductive cycle. Ecoscience 14:306-313

Troxell-Smith SM, Tutka MJMJ, Albergo JM, Balu D, Brown JS, Leonard JP (2016) Foraging decisions in wild versus domestic Mus musculus: what does life in the lab select for? Behav Process 122:43-50. https://doi.org/10.1016/j.beproc.2015.10.020

von Uexküll J (1909) Umwelt und Innenwelt der Tiere [Environment and inner world of animals]. Springer, Berlin

Webster DB, Strother WF (1972) Middle ear morphology and auditory sensitivity of heteromyid rodents. Am Zool 12:727

Wolff GE, Wittrock RA, Crosby JD, Roberts DA (2000) Differences in daily stress, mood, coping, and eating behavior in binge eating and nonbinge eating college women. Addict Behav 25:205216

Xia X, Millar JS (1988) Paternal behavior by Peromyscus leucopus in enclosures. Can J Zool 66:1184-1187. https://doi.org/10.1139/z88173

Ylönen H (1989) Weasels Mustela nivalis suppress reproduction in cyclic bank voles Clethrionomys glareolus. Oikos 55:138-140. https://doi. org/10.2307/3565886 
Ylönen H, Eccard JA, Jokinen I, Sundell J (2006) Is the antipredatory response in behaviour reflected in stress measured in faecal corticosteroids in a small rodent? Behav Ecol Sociobiol 60:350-358. https://doi.org/10.1007/s00265-006-0171-7

Ylönen H, Kojola T, Viitala J (1988) Changing female spacing behaviour and demography in an enclosed breeding population of Clethrionomys glareolus. Holarct Ecol 11:286-292
Ylönen H, Sundell J, Tiilikainen R, Eccard JA, Horne T (2003) Weasels' (Mustela nivalis nivalis) preference for olfactory cues of the vole (Clethrionomys glareolus). Ecology 84(6):1447-1452

Publisher's note Springer Nature remains neutral with regard to jurisdictional claims in published maps and institutional affiliations. 